\title{
High prevalence of diarrheagenic Escherichia coli carrying toxin-encoding genes isolated from children and adults in southeastern Brazil
}

\author{
Liliana Cruz Spano ${ }^{1 *}$, Keyla Fonseca da Cunha ${ }^{2}$, Mariane Vedovatti Monfardini ${ }^{3}$, \\ Rita de Cássia Bergamaschi Fonseca ${ }^{4}$ and Isabel Christina Affonso Scaletsky ${ }^{3}$
}

\begin{abstract}
Background: Diarrheagenic Escherichia coli (DEC) are important bacterial causes of childhood diarrhea in Brazil, but its impact in adults is unknown. This study aimed at investigating DEC among children and adults living in endemic areas.

Methods: A total of 327 stools specimens were collected from children $(n=141)$ and adults $(n=186)$ with diarrhea attending health centers. Diarrheagenic E. coli (DEC) were identified by their virulence genes (multiplex polymerase chain reaction) and HEp-2 cell adherence patterns.

Results: DEC were detected in 56 (40\%) children and 74 (39\%) adults; enteroaggregative E. coli (EAEC) (23\%) was the most prevalent pathotype, followed by diffusely adherent E. coli (DAEC) (13\%), and occurred at similar frequencies in both diarrheal groups. Atypical enteropathogenic E. coli (aEPEC) strains were recovered more frequently from children (6\%) than from adults (1\%). Twenty-six percent of the EAEC were classified as typical EAEC possessing aggR gene, and carried the aap gene. EAEC strains carrying aggR-aap-aatA genes were significantly more frequent among children than adults $(p<0.05)$. DAEC strains possessing Afa/Dr. genes were detected from children (10\%) and adults (6\%). EAEC and DAEC strains harboring genes for the EAST1 (astA), Pet, Pic, and Sat toxins were common in both diarrheal groups. The astA and the porcine AE/associated adhesin (paa) genes were found in most of aEPEC strains. High levels of resistance to antimicrobial drugs were found among DAEC and aEPEC isolates.
\end{abstract}

Conclusion: The results show a high proportion of EAEC and DAEC carrying toxin-encoding genes among adults with diarrhea.

Keywords: Diarrheagenic E. coli, Children, Adults

\section{Background}

Diarrheal disease caused by Escherichia coli is a major public health concern around the world [1]. Diarrheagenic Escherichia coli (DEC) strains comprise the most common bacterial pathogens worldwide [2,3]. DEC strains are classified into six groups based on clinical, epidemiological and virulence traits: enteropathogenic Escherichia coli

\footnotetext{
* Correspondence: liliana.spano@ufes.br

'Departamento de Patologia, Laboratório de Virologia e Gastrenterite Infecciosa, Centro de Ciências da Saúde, Universidade Federal do Espírito Santo, Av. Marechal Campos 1468, 29043-900, Maruípe, Vitória, Espírito Santo, Brazil

Full list of author information is available at the end of the article
}

(EPEC), enteroaggregative E. coli (EAEC), diffusely adherent $E$. coli (DAEC), enterotoxigenic E. coli (ETEC), enteroinvasive E. coli (EIEC) and enterohemorrhagic E. coli (EHEC) [2]. EPEC, EAEC, and DAEC show characteristics adhesion patterns (localized, aggregative and diffuse, respectively) to epithelial cells. EPEC is characterized by the presence of intimin (eae) gene causing attachment and effacement on intestinal epithelial cells and the bundleforming pili $(b f p)$ gene encoded in the EPEC adherence factor (EAF) plasmid. Typical EPEC is characterized by the presence of both eae and $b f p$ genes, while atypical EPEC possess the eae gene alone. EAEC is characterized 
by the virulence factors that is present in the $60 \mathrm{MDa}$ plasmid, which includes aggregative adherence factors (AAFs), the transcriptional activator $a g g R$, anti-aggregation protein (aap) gene, and anti-aggregation protein transporter (aatA) gene. DAEC is characterized by the presence of Afa/Dr. adhesin genes. ETEC is characterized by the presence of heat labile (elt) and/or heat-stable (est) toxin genes. EIEC is characterized by the presence of an invasion plasmid, which encodes a number of genes for invasion that includes the ipaH gene. STEC is characterized by the presence of toxin genes (stxi and stx2) [3].

Diarrheal disease remains an important public health problem for children in developing areas of Brazil, including peri urban and rural areas. In these regions, the poor quality or absence of sanitization and of a clean water supply for the population introduce risk factors for the mortality and morbidity of childhood diarrhea. In a previous study conducted in the city of Vitória (same geographical region of the present investigation), DEC strains, especially EAEC, DAEC, and EPEC were found in $45 \%$ of cases of diarrhea in children from rural communities [4]. We conducted a survey of causative agents of diarrhea among children and adults living in peri urban areas of Brazil with poor hygiene and sanitization conditions.

\section{Methods}

\section{Study subjects}

The study was conducted between January 2008 and February 2009 in the city of Vitória, Espírito Santo. The study was part of a study with the aim of identifying risk factors for diarrhea in rural and peri urban areas with poor hygiene and sanitation conditions in southeastern Brazil [4]. Thirty-one different health centers provided stool samples. All enrolled patients (children and adults) were outpatients visiting the clinical health with acute diarrhea as reported by the physicians. The diarrhea was characterized by the occurrence of three or more loose, liquid or watery stools or at least one blood loose stool in a $24 \mathrm{~h}$ period [5]. The patients had no taken antibiotics in the week preceding the sampling. Clinical symptoms, including fevers, vomiting, abdominal pain, or dehydration were reported by the physicians.

Stool samples were collected and placed in Cary-Blair transport medium, and transported in iced boxes within $4 \mathrm{~h}$ to the laboratory at the Universidade Federal do Espírito Santo. Samples were inoculated onto the surface of MacConkey and Hektoen plates (Oxoid, Hampshire, UK) for the selection of E. coli, Shigella, and Salmonella isolates. After incubation for $24 \mathrm{~h}$ at $37^{\circ} \mathrm{C}$, four lactosefermenting colonies with typical $E$. coli morphology, and two non-lactose-fermenting colonies were subjected to biochemical tests for identification. All E. coli strains were maintained in nutrient agar (Kasvi, Italy) slants at room temperature. Investigation of stool samples for parasites was performed by direct examination of stools after sedimentation in Lugol's iodine solution [6].

\section{Detection of diarrheagenic E. coli by multiplex PCRs}

All $E$. coli isolates were subjected to two multiplex PCRs, as previously described, with some modifications [7]. PCR1 assay contained a primer mix for the detection of the following virulence markers: E. coli attaching and effacing (eae) gene (for detection of typical and atypical EPEC), EAF plasmid (for detection of typical EPEC strains), and the antiaggregation protein transporter gene (aatA; previously referred to as CVD432 or the AA probe) (for detection of EAEC strains). Primers specific for the detection of DAEC Afa/Dr. $(a f a B-C)$ strains were subsequently included into this multiplex PCR. PCR2 assay contained primers specific for elt and est. (enterotoxins of ETEC), ipaH (invasion plasmid antigen $\mathrm{H}$ found in EIEC and Shigella), and stx 1 and stx2 (Shiga toxins 1, 2 and variants of STEC). PCR1 assay identified EAEC, DAEC, and tEPEC by the presence of eae and $b f p A$, and aEPEC by the presence of only eae. PCR2 assay identified ETEC, EIEC, and STEC.

Three to six bacterial colonies from each stool sample were pooled for template DNA preparation immediately prior to PCR testing, suspended in $300 \mu \mathrm{L}$ of sterile water, and boiled for $10 \mathrm{~min}$. A $5-\mu \mathrm{L}$ aliquot of this suspension was added to $50 \mu \mathrm{L}$ of the PCR mixture $\left(50 \mathrm{mM} \mathrm{KCl}, 10 \mathrm{mM}\right.$ Tris- $\mathrm{HCl}$ [pH 8.3], $1.5 \mathrm{mM} \mathrm{MgCl}_{2}$, $2 \mathrm{mM}$ of each deoxynucleoside triphosphate), 1.5 $\mathrm{U}$ of AccuPrime Taq DNA polymerase, and $5 \mu \mathrm{M}$ of each set of primers except for the ipaH primers, which used $10 \mu \mathrm{M}$. The reactions were run in a thermal cycler (model system 2400; Perkin-Elmer Corporation, Norwalk, Conn.) with the following cycling conditions: $94{ }^{\circ} \mathrm{C}$ for $5 \mathrm{~min}, 40$ cycles of denaturation at $95{ }^{\circ} \mathrm{C}$ for $1 \mathrm{~min}$, annealing at $58{ }^{\circ} \mathrm{C}$ (assay 1 ) or $50{ }^{\circ} \mathrm{C}$ (assay 2) for $1 \mathrm{~min}$ and primer extension at $72{ }^{\circ} \mathrm{C}$ for 2 min followed by a final extension at $72{ }^{\circ} \mathrm{C}$ for $7 \mathrm{~min}$. PCR products $(10 \mu \mathrm{L})$ were visualized after electrophoresis in $2 \%$ agarose gels in Tris-borate-EDTA buffer and ethidium bromide staining. In all assays, a mixture of DNA from the prototype EPEC E2348/69, EAEC 042, DAEC C1845, ETEC H10407, EIEC EDL1284, and STEC EDL931 strains [2] served as the positive control, while E. coli K12 DH5 $\alpha$ was the negative control [8].

All DEC strains were submitted to slide agglutination with polyvalent and monovalent antisera (PROBAC, São Paulo, Brazil) against $\mathrm{O}$ antigens of EPEC serogroups (O26, O55, O86, O111, O114, O119, O125, O126, O127, O128ab, O142, O158), and EHEC O157. All E. coli strains were kept in nutrient agar slants at room temperature. 


\section{Detection of virulence markers by PCR}

Primers and PCR conditions for detecting sequences encoding 17 putative virulence genes are described in Table 1. A DNA template was prepared by boiling a suspension of 5 colonies in $100 \mu$ listilled water. The following $E$. coli strains where used as controls for detection of target genes: 042 (aggR, aap, aafA, pet, ast A, pic) [9], 17-2 (aggA) [10], RN785-1 (agg3A, irp2) [11], EDL933 (hdaA, chuA), FBC114 (sat) [12], iucA [13], C1845 (afaE, daaE) [14], 2787 (aida/aah) [15], and HSP7-1 (paa) [16].

\section{HEp-2 adherence assay}

E. coli isolates were subjected to HEp-2 adherence tests by the method originally described by Scaletsky et al. [17], with slight modifications. Briefly, monolayers of $10^{5}$ HEp-2 cells were grown in Dulbecco modified Eagle medium containing $10 \%$ fetal bovine in 24-well tissue culture plates (Falcon Becton Dickinson). Bacterial strains were grown statically in $2 \mathrm{ml}$ of brain heart infusion for 16-18 h. The monolayers were infected with $\sim 3$ X $10^{7}$ bacteria ( $20 \mu \mathrm{l}$ of bacterial cultures added to $1 \mathrm{ml}$ of DMEM) and incubated at $37{ }^{\circ} \mathrm{C}$ for $3 \mathrm{~h}$. The infected monolayers were washed with sterile PBS, fixed with methanol, stained with Giemsa stain, and examined by light microscopy for adherence pattern.

\section{Antimicrobial susceptibility testing}

Antimicrobial susceptibility tests were performed employing the disc diffusion method on Mueller-Hinton agar, following recommendations of the Clinical and Laboratory Standards Institute [18]. One colony of each E. coli isolate taken from a nutrient agar culture was inoculated into $10 \mathrm{~mL}$ of sterile water. The resulting suspension was applied to the surface of a $14-\mathrm{cm}$ plate of Muller Hinton agar (Difco) and spread evenly with a

Table 1 Primers used in polymerase chain reaction analysis

\begin{tabular}{|c|c|c|c|c|}
\hline Gene & Description & Primer Sequence (5'- 3') & PCR product & Reference \\
\hline$\overline{a g g R}$ & Transcriptional activator & $\begin{array}{l}\text { CTAATTGTACAATCGATGTA } \\
\text { ATGAAGTAATTCTTGAAT }\end{array}$ & $308 \mathrm{bp}$ & {$[37]$} \\
\hline aap & Antiaggregation protein & $\begin{array}{l}\text { CTITCTGGCATCTTGGGT } \\
\text { GTAACAACCCCTTTGGAAGT }\end{array}$ & $232 \mathrm{bp}$ & {$[37]$} \\
\hline $\operatorname{agg} A$ & AAF/I fimbria subunit & $\begin{array}{l}\text { TTAGTCTTCTATCTAGGG } \\
\text { AAATTAATTCCGGCATGG }\end{array}$ & $450 \mathrm{bp}$ & {$[37]$} \\
\hline$a a f A$ & AAF/Il fimbria subunit & $\begin{array}{l}\text { ATGTATTIITAGAGGTTGAC } \\
\text { TATTATATTGTCACAAGCTC }\end{array}$ & $518 \mathrm{bp}$ & {$[37]$} \\
\hline $\operatorname{agg}-3 \mathrm{~A}$ & AAF/III fimbria subunit & $\begin{array}{l}\text { GTATCATTGCGAGTCTGGTATTCAG } \\
\text { GGGCTGTTATAGAGTAACTTCCAG }\end{array}$ & $462 \mathrm{bp}$ & {$[38]$} \\
\hline had & AAF/IV fimbria subunit & $\begin{array}{l}\text { TCCATTATGTCAGGCTGCAA } \\
\text { GGCGTTAACGTCTGATTCC }\end{array}$ & $411 \mathrm{bp}$ & [41] \\
\hline paa & Porcine AE/associated adhesin & $\begin{array}{l}\text { ATGAGGAACATAATGGCAGG } \\
\text { TCTGGTCAGGTCGTCAATAC }\end{array}$ & $357 \mathrm{bp}$ & \\
\hline aida/aah & AIDA-I adhesin & $\begin{array}{l}\text { TCGATACCGAAACGCATACGCAGA } \\
\text { ACGCCGATCGGTGATGATGAAGAT }\end{array}$ & $204 \mathrm{bp}$ & \\
\hline$a f a E$ & Afa-I afimbrial adhesin & $\begin{array}{l}\text { CGAAAACGGCACTGACAAG } \\
\text { AGGCTITCCGTGAATACAACC }\end{array}$ & $230 \mathrm{bp}$ & [34] \\
\hline daaE & F1845 fimbrial adhesin & $\begin{array}{l}\text { TGACTGTGACCGAAGAGATGC } \\
\text { TTAGTTCGTCCAGTAACCCCC }\end{array}$ & $380 \mathrm{bp}$ & [34] \\
\hline sat & Secreted autotransporter toxin & $\begin{array}{l}\text { CTCATTGGCCTCACCGAACGG } \\
\text { GCTGGCAGCTGTGTCCACGAG }\end{array}$ & $299 \mathrm{bp}$ & \\
\hline pic & Serine protease precursor & $\begin{array}{l}\text { ACTGGCGGACTCATGCTG T } \\
\text { AACCCTGTAAGAAGACTGAGC }\end{array}$ & $387 \mathrm{bp}$ & \\
\hline pet & Plasmid-encoded toxin & $\begin{array}{l}\text { GACCATGACCTATACCGACAGC } \\
\text { CCGATTTCTCAAACTCAAGACC }\end{array}$ & $600 \mathrm{bp}$ & \\
\hline ast $A$ & EAST1 heat-stable toxin & $\begin{array}{l}\text { CCATCAACACAGTATATCCGA } \\
\text { GGTCGCGAGTGACGGCTITGT }\end{array}$ & $111 \mathrm{bp}$ & \\
\hline chuA shuA & Heme receptor & $\begin{array}{l}\text { ATCTGCTGCGTCATGTTCCT } \\
\text { GTAGTGGTCATACCTITGAGC }\end{array}$ & $1700 \mathrm{bp}$ & \\
\hline IUCA & Aerobactin sintase & $\begin{array}{l}\text { AGTCTGCATCTTAACCTTCA } \\
\text { CTCGTTATGATCGTTCAGAT }\end{array}$ & $1100 \mathrm{bp}$ & \\
\hline irp2 & Iron chelating & $\begin{array}{l}\text { AAGGATTCGCTGTTACCGGAC } \\
\text { TCGTCGGGCAGCGTTCTTCT }\end{array}$ & $264 \mathrm{bp}$ & \\
\hline
\end{tabular}


sterile cotton-tipped applicator. The plates were incubated at $37^{\circ} \mathrm{C}$ for $30 \mathrm{~min}$ before the application of antibiotic discs. The antibiotic discs $(6 \mathrm{~mm}$; all obtained from Oxoid) were amikacin $(30 \mu \mathrm{g})$, ampicillin $(10 \mu \mathrm{g})$, amoxicillin-clavulanic acid $(30 \mu \mathrm{g})$, cefotaxime $(30 \mu \mathrm{g})$, choramphenicol $(30 \mu \mathrm{g})$, ciprofloxacin $(5 \mu \mathrm{g})$, gentamicin $(10 \mu \mathrm{g})$, imipenem $(10 \mu \mathrm{g})$, cotrimoxazole $(25 \mu \mathrm{g})$; tetracycline $(30 \mu \mathrm{g})$, and trimethoprim $(5 \mu \mathrm{g})$. The inhibition zone diameters were measured in millimeters and interpreted in accordance with manufacturers' recommendations. E. coli $\mathrm{NCTC} 10418$ and E. coli K-12 C600 were used as controls.

\section{Statistical analysis}

The statistical analyses were performed using the SPSS version 17.0 (SPSS Inc., Chicago, IL). Statistical differences were evaluated by chi-square or Fisher's exact tests. A $p$ value $<0.05$ was considered statistically significant.

\section{Results}

\section{Subjects}

From January 2008 and February 2009, a total of 327 cases of diarrhea were recruited in this study. They were divided into two groups, 141 children $(<18$ years of age) and 186 adults ( $\geq 18$ years of age), were recruited in this study. Of the 141 children, 75 (53.2\%) were younger than 2 years, 49 (34.7\%) were between 2 and 10 years, and $17(12.1 \%)$ were younger than 18 years of age. Among adults, 51 (27.4\%) were between 18 and 30 years, $66(35.5 \%)$ were between 31 and 50, and 69 (37.1\%) were older than 50 years of age.

\section{Prevalence of DEC and enteropathogens}

E. coli $(n=1200)$ strains isolated from 280 of 327 cases were categorized into different pathotypes of DEC based on the results of two multiplex PCRs. Strains negative for DEC markers were further examined for their HEp-2 cell adherence patterns. Tables 2 and 3 show the characteristics and isolation frequency of DEC strains. DEC pathotypes were detected in 56 (39.7\%) diarrheagenic children and 74 (38.8\%) diarrheagenic adults. None of the DEC strains belonged to a classical EPEC serogroup. EAEC and DAEC were most common, each detected in $23 \%$ and $13 \%$, in both diarrheal groups. Atypical EPEC (only eae) was more frequently detected among diarrheagenic children (5.7\%) than diarrheagenic adults

Table 2 Distribution of diarrheagenic E. coli (DEC) isolated from children and adults attending health centers in Southeastern Brazil

\begin{tabular}{|c|c|c|c|c|c|}
\hline \multirow{2}{*}{$\begin{array}{l}\text { DEC (type and } \\
\text { genes) } n=130\end{array}$} & \multirow[t]{2}{*}{ Number (\%) } & \multirow{2}{*}{$\begin{array}{l}\% \text { of all patients } \\
(n=327)\end{array}$} & \multicolumn{2}{|l|}{ No. of strains (\%) } & \multirow[t]{2}{*}{$p$ value } \\
\hline & & & Children $(n=141)$ & Adults $(n=186)$ & \\
\hline EAEC & 76 & 23.2 & $32(22.6)$ & $44(23.6)$ & 0,8952 \\
\hline aatA & $15(19.7)$ & 4.6 & $12(8.5)$ & $3(1.6)$ & 0.0027 \\
\hline AA phenotype & $60(78.9)$ & 18.3 & $26(18.4)$ & $34(18.3)$ & 1.0000 \\
\hline CLA phenotype & $16(21.1)$ & 4.9 & $4(2.8)$ & $12(6.5)$ & 0.1952 \\
\hline DAEC & 42 & 12.8 & $18(12.8)$ & $24(12.9)$ & 0.3215 \\
\hline$a f a / d r$ & $25(59.5)$ & 7.6 & $14(9.9)$ & $11(5.9)$ & 0.2091 \\
\hline DA phenotype & $17(40.5)$ & 5.2 & $4(2.8)$ & $13(7.0)$ & 0.7628 \\
\hline EPEC & 10 & 3.1 & $8(5.7)$ & $2(1.1)$ & $N D^{a}$ \\
\hline eae & $10(100)$ & 3.1 & $8(5.7)$ & $2(1.1)$ & ND \\
\hline$e a e+b f p A$ & 0 & 0 & 0 & 0 & ND \\
\hline ETEC & 2 & 0.6 & 0 & $2(1.1)$ & ND \\
\hline elt & $1(50.0)$ & 0 & 0 & $1(0.5)$ & ND \\
\hline est & $1(50.0)$ & 0 & 0 & $1(0.5)$ & ND \\
\hline EIEC & 0 & 0 & 0 & 0 & ND \\
\hline $\mathrm{ipaH}$ & 0 & 0 & 0 & 0 & \\
\hline EHEC & 0 & 0 & 0 & 0 & ND \\
\hline stx1or stx2 & 0 & 0 & 0 & 0 & \\
\hline Mixed infection & 6 & 1.8 & $2(1.4)$ & $4(2.2)$ & 0.7024 \\
\hline EAEC + DAEC & 3 & 0.9 & $1(0.7)$ & $2(1.1)$ & ND \\
\hline EAEC + ETEC & 1 & 0.3 & 0 & $1(0.5)$ & ND \\
\hline $\mathrm{EAEC}+\mathrm{aEPEC}$ & 1 & 0.3 & 0 & $1(0.5)$ & ND \\
\hline DAEC + aEPEC & 1 & 0.3 & $1(0.7)$ & 0 & ND \\
\hline
\end{tabular}

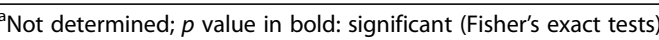


Table 3 Distribution of related-virulence genes among diarrheagenic E. coli (DEC) isolated from children and adults attending health centers in Southeastern Brazil

\begin{tabular}{|c|c|c|c|c|c|}
\hline \multirow[t]{2}{*}{ DEC group } & \multirow[t]{2}{*}{ Virulence gene } & \multirow[t]{2}{*}{ Number (\%) } & \multicolumn{2}{|l|}{ No. of strains (\%) } & \multirow[t]{2}{*}{$p$ value } \\
\hline & & & Children $(n=141)$ & Adults $(n=186)$ & \\
\hline \multirow[t]{15}{*}{ EAEC } & & 76 & & & \\
\hline & aatA & $15(19.7)$ & $12(8.5)$ & $3(1.6)$ & 0.0027 \\
\hline & $a a p$ & $21(27.6)$ & $15(10.6)$ & $6(3.2)$ & 0.0107 \\
\hline & $a g g R$ & $20(26.3)$ & $14(9.9)$ & $6(3.2)$ & 0.0181 \\
\hline & $\operatorname{agg} A$ & $1(1.3)$ & $1(0.7)$ & 0 & $N D^{a}$ \\
\hline & aafA & 0 & 0 & 0 & ND \\
\hline & $\operatorname{agg} 3 A$ & $7(9.2)$ & $4(2.8)$ & $3(1.6)$ & 0.4698 \\
\hline & hdaA & $5(6.6)$ & $4(2.8)$ & $1(0.5)$ & 0.1696 \\
\hline & pet & $42(55.3)$ & $17(12.1)$ & $25(13.4)$ & 0.7416 \\
\hline & astA & $17(22.3)$ & $8(5.7)$ & $9(4.8)$ & 0.8040 \\
\hline & pic & $31(40.8)$ & $14(9.9)$ & $17(9.1)$ & 0.8502 \\
\hline & sat & $11(14.5)$ & $5(3.5)$ & $6(3.2)$ & 1.0000 \\
\hline & irp2 & $29(38.1)$ & $11(7.8)$ & $18(9.7)$ & 0.6951 \\
\hline & incA & $27(35.5)$ & $13(9.2)$ & $14(7.5)$ & 0.6858 \\
\hline & chuA & $14(18.4)$ & $6(4.3)$ & $8(4.3)$ & 1.0000 \\
\hline \multirow[t]{9}{*}{ DAEC } & & 42 & & & \\
\hline & $a f a B-C$ & $25(59.5)$ & $14(9.9)$ & $11(5.9)$ & 0.2091 \\
\hline & afaE & 0 & 0 & 0 & 0 \\
\hline & daaE & 0 & 0 & 0 & 0 \\
\hline & aida/aah & 0 & 0 & 0 & 0 \\
\hline & ast $A$ & $6(14.2)$ & $4(2.8)$ & $2(1.1)$ & ND \\
\hline & pic & $3(7.1)$ & $1(0.7)$ & $2(1.1)$ & ND \\
\hline & pet & $23(54.8)$ & $6(4.3)$ & $17(9.1)$ & 0.1251 \\
\hline & sat & $11(26.2)$ & $3(2.1)$ & $8(4.3)$ & 0.3620 \\
\hline \multirow[t]{3}{*}{ aEPEC } & & 10 & & & \\
\hline & astA & $10(100.0)$ & $8(5.7)$ & $2(1.1)$ & ND \\
\hline & paa & $4(40.0)$ & $4(2.8)$ & 0 & $\mathrm{ND}$ \\
\hline
\end{tabular}

${ }^{a} N D:$ Not determined; $p$ value in bold: significant (Fisher's exact tests)

(1.1\%). LT-ETEC was found in two diarrheagenic adults (0.7\%). Mix DEC infections were detect in five patients; two of them harbored EAEC and DAEC, one harbored EAEC and aEPEC, one DAEC and EPEC, and one EAEC and ETEC. No EIEC, EHEC or STEC were detected in this study. Other enteric pathogens isolated were Shigella (1.2\%) and Salmonella (0.3\%). Parasites (Ascaris, Giardia, Ancylostoma, Strongyloides or Taenia) were detected in $7 \%$ of stool samples. Mixed infections were presented in $22(15.6 \%)$ cases and 12 (2.9\%) controls $(P<0.05)$.

\section{Characterization of EAEC, DAEC and aEPEC isolates}

Of a total of 76 EAEC isolates, 15 (19.7\%) of EAEC were aatA positive. EAEC aatA-positive strains were isolated significantly more often from diarrheagenic children than diarrheagenic adults $(p<0.05)$ (Table 2$)$. The majority of the EAEC isolates (79\%) produced the characteristic AA pattern on HEp-2 cells. Sixteen (21\%) EAEC isolates produced the chain-like adherence (CLA) pattern, characterized by bacteria attaching on both coverslip and HEp-2 cell surfaces forming long chain aggregates, concomitantly with the AA pattern [19]. All EAEC isolates were tested by PCR to detect genes for the proposed EAEC virulence factors, such as Aap, AggR, AAF/I, AAF/II, AAF/III, Hda, Pet, EAST1, Pic, Irp2, IucA, and ChuA. As shown in Table 3, pet was the most frequently detected (55.3\%) followed by pic (40.8\%), iucA (35.5\%), irp2 (28.1\%), aap (27.6\%), aggR (26.3), and chuA (18.4\%). One strain harbored AAF/I ( $\operatorname{aggA})$, seven strains harbored AAF/III $(\operatorname{agg} 3 A)$, and five strains harbored AAF/IV (hdaA). EAEC strains carrying the aagR-aap-aatA genes were isolated 
significantly more often from diarrheagenic children than diarrheagenic adults $(p<0.05)$ (Table 3$)$.

There were a total of 42 DAEC, of which 25 (59.5\%) harbored adhesins from the Afa/Dr. family (Table 2). DAEC strains possessing Afa/Dr. genes were detected in both children (10\%) and adults (6\%) groups, and none of these strains presented the adhesin-encoded genes afaE, daaE and aida (Table 3). All DAEC strains were tested by PCR to detect the toxin-encoding genes astA, pet, pic, and sat. As shown Tables 3, 23 (54.8\%) of the strains were positive for pet. The sat gene was found in 11 (26.2\%), while astA and pic were found in $6(14.2 \%)$ and $3(7.1 \%)$ of strains, respectively.

Atypical EPEC (only eae) was more frequently detected among diarrheagenic children (5.7\%) than diarrheagenic adults (1.1\%) (Table 2). All strains harbored the astA gene, and $40 \%$ of them also harbored the porcine AE-associated adhesin (paa) gene (Table 3). Strains were examined for adhesion to HEp-2 and none of them were adherent.

EAEC, DAEC, and aEPEC isolates were tested for their susceptibilities to 12 antimicrobial agents (Table 4). The EAEC isolates had low frequencies of antimicrobial resistance, while high-resistance rates were found among DAEC isolates, being ampicillin, cefotaxime and cotrimoxazole the most prevalent, each detected in $75 \%$. Half of aEPEC isolates were resistant to at least 8 antimicrobial drugs. Since it is well-known that antibiotic resistance is apparently associated with plasmids, we examined plasmid carriage of 10 strains of DAEC and aEPEC. As shown in Figs. 1 and 2, different plasmid profiles were seen after DNA extraction by alkaline lyses method [20] in DAEC and aEPEC strains isolated from both children and adults (Figs. 1 and 2).

\section{Discussion}

Despite the abundance of reports on diarrheal disease in children under five years of age, this study is one of the few to include the identification of all six DEC pathotypes in all age individuals. Our study has shed light on the little-known issue of DEC infections in adult patients attending health centers. Adults rarely visit a health care when they have diarrhea, unless they perceive the diarrhea as being serious. We demonstrated that DEC pathotypes were commonly found in diarrheagenic adults (40\%). EAEC (23\%) and DAEC (13\%) were the most prevalent DEC pathotypes in both diarrheal groups; whereas aEPEC strains were recovered more frequently from diarrheagenic children (6\%) than from diarrheagenic adults (1\%). ETEC accounted for $1.5 \%$ of DEC, and we did not find EIEC and EHEC strains, indicating their limited role in childhood diarrhea in Brazil. Our findings are in agreement with a previous study conducted in rural communities in the city of São Mateus (same geographical region of the present investigation), showing high prevalence of DEC (45\%) in children with diarrhea, EAEC (21\%) as the most frequent DEC, followed by DAEC (12\%) and EPEC (9\%) [4]. In another study, DAEC was significantly associated with diarrhea in children older than one year of age (18.3\%) at the emergency room of Hospital de Pediatria in the city of Vitória [21]. Several other studies conducted in Brazil have also shown that EAEC and DAEC strains are frequently detected in children with diarrhea [22-24]. aEPEC has been increasingly reported and was recently implicated as a cause of childhood diarrhea in different urban centers of Brazil $[25,26]$.

The terms typical EAEC and atypical EAEC have been suggested to refer to EAEC strains harboring or lacking the regulator AggR, respectively. Some studies have demonstrated an association of typical EAEC with diarrhea $[25,27,28]$. In our study, aggR-positive strains were isolated significantly more often from diarrheagenic children than from diarrheagenic adults $(p<0.05)$. Interesting, AA plasmid-positive EAEC was dominant among children and AA plasmid-negative EAEC was dominant

Table 4 Antimicrobial susceptibility of diarrheagenic E. coli isolated from children and adults attending health centers in Southeastern Brazil

\begin{tabular}{|c|c|c|c|c|c|c|c|c|c|c|c|}
\hline \multirow[t]{2}{*}{ DEC group } & \multicolumn{11}{|c|}{ Susceptibility, n (\%) } \\
\hline & AMK & AMP & AMC & CTX & $\mathrm{CHL}$ & CIP & GEN & IPM & SXT & TET & $\mathrm{TIC}$ \\
\hline \multicolumn{12}{|l|}{ EAEC } \\
\hline Children $(n=30)$ & $1(3.3)$ & 0 & 0 & 0 & 0 & $1(3.3)$ & $1(3.3)$ & 0 & 0 & $1(3.3)$ & 0 \\
\hline Adults $(n=46)$ & $1(2.2)$ & $2(4.3)$ & $3(6.5)$ & $4(8.7)$ & $2(4.3)$ & $3(6.5)$ & $2(4.3)$ & $2(4.3)$ & $2(4.3)$ & $5(10.9)$ & $2(4.3)$ \\
\hline \multicolumn{12}{|l|}{ DAEC } \\
\hline Children $(n=18)$ & $2(11.1)$ & $7(38.9)$ & 0 & $8(44.4)$ & $3(16.7)$ & $10(55.5)$ & 0 & 0 & $4(22.2)$ & $1(5.5)$ & $3(16.7)$ \\
\hline Adults $(n=24)$ & $5(20.8)$ & $11(45.8)$ & $2(8.3)$ & $14(58.3)$ & $4(16.7)$ & $14(58.3)$ & 0 & $4(16.7)$ & $5(20.8)$ & $2(8.3)$ & $4(16.7)$ \\
\hline \multicolumn{12}{|l|}{ aEPEC } \\
\hline Children $(n=8)$ & $4(50.0)$ & $6(75.0)$ & $3(37.5)$ & $6(75.0)$ & $5(62.5)$ & $5(62.5)$ & $5(62.5)$ & $5(62.5)$ & $6(75.0)$ & $5(62.5)$ & $5(62.5)$ \\
\hline Adults $(n=2)$ & 0 & 0 & 0 & 0 & 0 & 0 & 0 & 0 & 0 & 0 & 0 \\
\hline
\end{tabular}

AMK Amikacin, AMP Ampicillin, AMC Amoxicillin-Clavulanic acid, CTX Cefotaxime, CLO Choramphenicol, CIP Ciprofloxacin, GEN Gentamicin, IPM Imipenem, SUT trimethoprim-sulfamethoxazole, TET Tetracycline, TIC Ticarcillin 


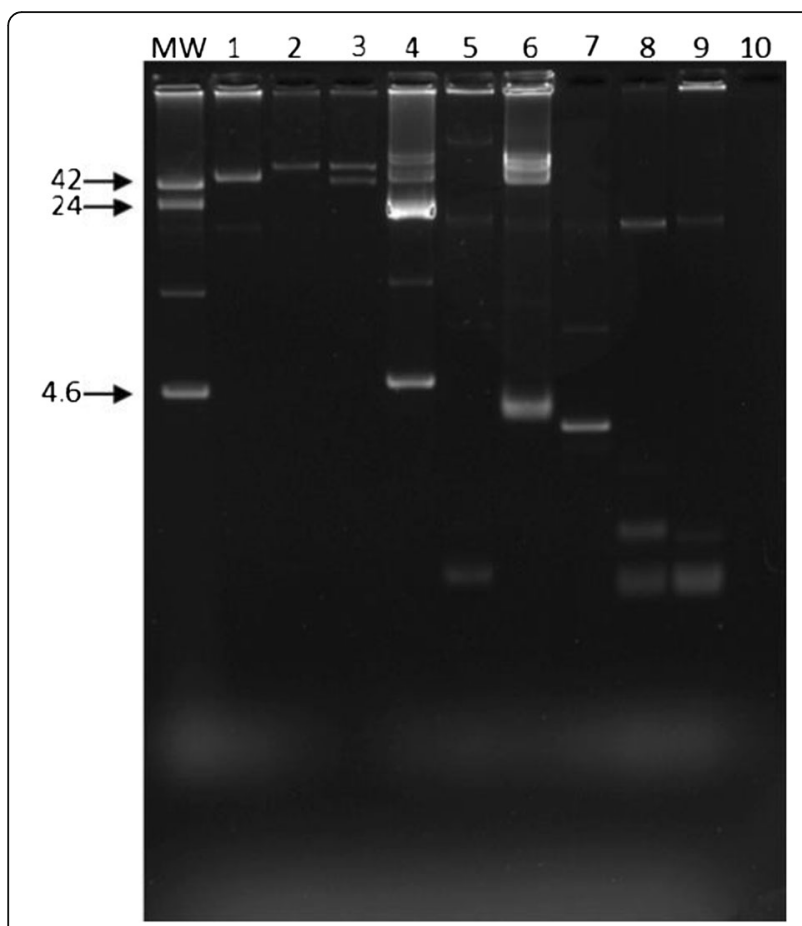

Fig. 1 Plasmid contents of aEPEC strains isolated from children (lanes 1-8) and adults (lans 9-10). MW, R861, E. coli strain carrying plasmids of known molecular sizes

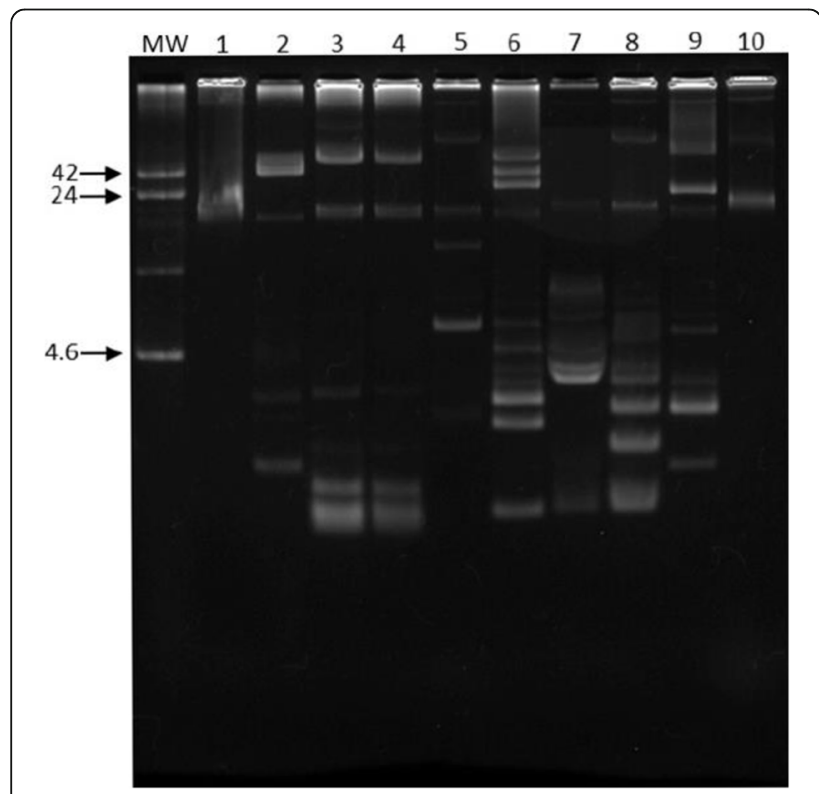

Fig. 2 Plasmid contents of DAEC strains isolated from children (lanes 1-5) and adults (lans 6-10). MW, R861, E. coli strain carrying plasmids of known molecular sizes among adults. Two hypotheses would be proposed: one is that there are different routes of infection to adults and children in the study area, another is that AA plasmid-negative strains could survive adaptively in adults, though children and adults are equally infected by both AA plasmid positive and negative EAEC. Twenty percent of our EAEC aatA-aggR positive strains simultaneously harbored the aap gene for dispersin. There appears to be a high conservation of the aatAaagR-aap locus in the pAA plasmid, as has been shown for the prototype 042 strains [29]. Most tEAEC did not harbor the four variants of AAFs, similarly to previous studies in Brazil [11, 22, 30].

The pathogenic mechanisms of EAEC infection are only partially understood. The varying presence of the different virulent factors indicates heterogeneity of the EAEC isolates [30]. It has been hypothesized that the combination of these genes increases strain virulence. Several different combinations of the virulence markers were found among the EAEC isolates. The most prevalent combination was pet and pic, found at similar frequencies in both diarrheal groups.

The adhesins of Afa/Dr. family have been implicated in DAEC pathogenesis. The prevalence of DAEC possessing Afa/Dr. genes in diarrheagenic children and diarrheagenic adults was similar. Germani et al. [31] demonstrated that, among DAEC strains, only those that were $\mathrm{Afa} / \mathrm{Dr} .^{+}$were found in higher frequency in diarrheic patients than asymptomatic controls. However, in some studies, DAEC Afa/Dr. ${ }^{+}$strains are isolated from cases of diarrhea and controls in similar frequencies [32, 33]. The afaE and daaE (F1845) genes were not found in any DAEC strains. In our study, a significant proportion of DAEC isolates carried a gene encoding for a toxin, such as Pet and Sat. In a recent Brazilian study, DAEC sat-positive strains were found to be associated with childhood diarrhea [34].

The porcine AE/associated adhesin (paa) gene has been found in a higher frequency among aEPEC from children with diarrhea than from controls $[16,35]$. In addition, the EAST1 toxin (astA) has been found in association with diarrheal disease among Brazilian children [36-38]. The analysis of the presence of those genes showed that all aEPEC isolates carried astA and $40 \%$ of them carried paa genes.

Our data show a high resistance rate in $E$. coli strains similar to those reported in previous studies $[39,40]$ and constitute a great concern in Brazil for public health. There was no significant difference in antibiotic resistance in E. coli strains isolated from children compared with strains from adults. Resistance to more than one antibiotic was found in approximately $60 \%$ of DAEC and aEPEC strains. The most commonly observed resistance was to ampicilin, cefotaxime and cotrimoxazole. 


\section{Conclusion}

Our results show a high proportion of DEC, where EAEC and DAEC predominate among children and adults with diarrhea. In addition, our results suggest that DEC carrying toxin-encoding genes seem to play an important role in causing sporadic diarrheal diseases in Brazil. Moreover, the findings reinforce our previous communications regarding the importance of DEC strains in childhood diarrhea in endemic areas of Brazil.

\section{Acknowledgments}

The authors thanks to the Municipality Laboratory of Vitória for the access of the clinical specimens. KFC and MVM were both supported with scholarship by the Foundation for Research and Innovation of Espírito Santo, Brazil.

\section{Funding}

This study was supported by grants of the Foundation for Science and Technology of Victoria Municipality (FACITEC) of Espírito Santo State, Brazil. The funding body had no participation in the design of the study and collection, analysis, and interpretation of data and in writing the manuscript.

\section{Availability of data and materials}

The data is available upon request. Please contact the corresponding author Liliana Cruz Spano, E-mail: liliana.spano@ufes.br.

\section{Authors' contributions}

LCS conceived and designed the study. ICSA assisted in the development of the study. Laboratory investigations and data analysis were performed by KFC, MMV, and RCBF. ICSA and LCS interpreted the data and drafted the manuscript. All the authors revised and approved the final manuscript.

\section{Ethics approval and consent to participate}

The study was approved by the Ethical Committee of the Universidade Federal do Espírito Santo, Brazil. Stool samples were obtained with the written informed consent from the adults and from the parents or guardians of the children.

\section{Consent to publication}

Not applicable.

\section{Competing interests}

The authors declare that they have no competing interests.

\section{Publisher's Note}

Springer Nature remains neutral with regard to jurisdictional claims in published maps and institutional affiliations.

\section{Author details}

'Departamento de Patologia, Laboratório de Virologia e Gastrenterite Infecciosa, Centro de Ciências da Saúde, Universidade Federal do Espírito Santo, Av. Marechal Campos 1468, 29043-900, Maruípe, Vitória, Espírito Santo, Brazil. ${ }^{2}$ Núcleo de Doenças Infecciosas, Departamento de Medicina Social, Centro de Ciências da Saúde, Universidade Federal do Espírito Santo, Vitória, Espírito Santo, Brazil. ${ }^{3}$ Departamento de Microbiologia, Imunologia e Parasitologia, Universidade Federal de São Paulo, Vitória, Espírito Santo, Brazil. ${ }^{4}$ Laboratório Central Municipal, Vitória, Espírito Santo, Brazil.

Received: 28 April 2017 Accepted: 30 November 2017 Published online: 18 December 2017

\section{References}

1. Kotloff KL, Nataro JP, Blackwelder WC, et al. Burden and aetiology of diarrhoeal disease in infants and young children in developing countries (the global enteric multicenter study, GEMS): a prospective, case-control study. Lancet. 2013;382:209-22.

2. Nataro JP, Kaper JB. Diarrheagenic Escherichia coli. Clin Microbiol Rev. 1998;11:142-201.
3. Croxen MA, Law RJ, Scholz R, Keeney KM, Wlodarska M, Finlay BB. Recent advances in understanding enteric pathogenic Escherichia coli. Clin Microbiol Rev. 2013;26:822-80.

4. Lozer DM, Souza TB, Monfardini MV, et al. Genotypic and phenotypic analysis of diarrheagenic Escherichia coli strains isolated from Brazilian children living in low socioeconomic level communities. BMC Infect Dis. 2013;8:418.

5. WHO. Diarrhoea. Available at: http://www.who.int/topics/diarrhoea/en/. Accessed 13 April 2017.

6. Murray PR 1999 Murray PR, Baron MA, Pfaller MA, Tenover FC, Yolken RH: Manual of Clinical Microbiology. Washington. ASM press;1999.

7. Aranda KR, Fagundes-Neto U, Scaletsky IC. Evaluation of multiplex PCRs for diagnosis of infection with diarrheagenic Escherichia coli and Shigella spp. J Clin Microbiol. 2004;42:5849-53.

8. Sambrook J, Fritsch EF, Maniatis T. Molecular cloning: a laboratory manual. 2nd ed. Cold Spring Harbor, NY: Cold Spring Harbor Laboratory Press; 1989.

9. Baudry B, Savarino SJ, Vial P, Kaper JB, Levine MM. A sensitive and specific DNA probe to identify enteroaggregative $E$. coli, a recently discovered diarrheal pathogen. J Infect Dis. 1990;161:1249-51.

10. NataroJP DY, Maneval DR, German AL, Martin WC, Levine MM. Aggregative adherence fimbriar II, a second fimbrial antigen mediating aggregative adherence in enteroaggregative Escherichai coli. Infect Immun. 1992;60:2297-304.

11. Zamboni A, Fabricotti SH, Fagundes-Neto U, Scaletsky IC. Enteroaggregative Escherichia coli virulence factors are found to be associated with infantile diarrhea in Brazil. J Clin Microbiol. 2004;42:1058-63.

12. Taddei CR, Moreno AC, Fernandes Filho A, Montemor LP, Martinez MP. Prevalence of secreted autotransporter toxin gene among diffusely adhering Escherichia coli isolated from stools of children. FEMS Microbiol Lett. 2003;227:249-53.

13. Okeke IN, Scaletsky ICA, Soars EH, MacFarlane LR, Torres AG. Molecular epidemiology of the iron utilization genes of enteroaggreagtive Escherichia coli. J Clin Microbiol. 2004:42:36-44.

14. Bilge S, Clausen C, Lau W, Moseley S. Molecular characterization of a fimbrial adhesin, F1845, mediating diffuse adherence of diarrhea-associated Escherichia coli to HEp-2 cells. J Bacteriol. 1989;171:4281-9.

15. Benz I, Schmidt MA. Cloning and expression of an adhesin (AIDA-I) involved in diffuse adherence of enteropathogenic Escherichia coli. Infect Immun. 1989:57:1506-11.

16. Scaletsky IC, Aranda KR, Souza TB, Silva NP. Adherence factors in atypical enteropathogenic Escherichia coli strains expressing the localized adherence-like pattern in HEp-2 cells. J Clin Microbiol. 2010;48:302-6.

17. Scaletsky ICA, Silva MLM, Trabulsi LR. Distinctive patterns of adherence of Enteropathogenic Escherichia coli to HeLa cells. Infect. Immunity. 1984:45:534-6.

18. CLSI. Clinical and laboratory standards institute. Performance standards for antimicrobial susceptibility testing; twenty-fifth informational supplement. CLSI document M 100-S25. Clinical and Laboratory Standards Institute: Pensylvania; 2015.

19. Gioppo NM, Elias WP Jr, Vidotto MC, et al. Prevalence of HEp-2 cell-adherent Escherichia coli and characterisation of enteroaggregative E. coli and chainlike adherent $E$. coli isolated from children with and without diarrhoea, in Londrina, Brazil. FEMS Microbiol Lett. 2000;190:293-8.

20. Birnboim HC, Doly JA. Rapid extraction procedure for screening recombinant plasmid DNA. Nucleic Acids Res. 1979;7:1513-23.

21. Spano LC, Sadovsky AD, Segui PN, et al. Age-specific prevalence of diffusely adherent Escherichia coli in Brazilian children with acute diarrhoea. J Med Microbiol. 2008:57:359-63.

22. Piva IC, Pereira AL, Ferraz LR, et al. Virulence markers of Enteroaggregative Escherichia coli isolated from children and adults with diarrhea in Brasilia. Brazil J Clin Microbiol. 2003;41:1827-32.

23. Regua-Mangia AH, Gomes TA, Vieira MA, Andrade JR, Irino K, Teixeira LM. Frequency and characteristics of diarrhoeagenic Escherichia coli strains isolated from children with and without diarrhoea in Rio de Janeiro, Brazil. J Inf Secur. 2004:48:161-7.

24. Rodrigues J, Thomazini CM, Morelli A, de Batista GC. Reduced etiological role for Enteropathogenic Escherichia coli in cases of diarrhea in Brazilian infants. J Clin Microbiol. 2004;42:398-400.

25. Araujo JM, Tabarelli GF, Aranda KR, et al. Typical enteroaggregative and atypical enteropathogenic types of Escherichia coli are the most prevalent diarrhea-associated pathotypes among Brazilian children. J Clin Microbiol. 2007:45:3396-9. 
26. Scaletsky IC, Souza TB, Aranda KR, Okeke IN. Genetic elements associated with antimicrobial resistance in enteropathogenic Escherichia coli (EPEC) from Brazil. BMC Microbiol. 2010;10:25.

27. Okeke IN, Lamikandra A, Czeczulin J, Dubovsky F, Kaper JB, Nataro JP. Heterogeneous virulence of enteroaggregative Escherichia coli strains isolated from children in Southwest Nigeria. J Infect Dis. 2000;181:252-60.

28. Sarantuya J, Nishi J, Wakimoto N, et al. Typical enteroaggregative Escherichia coli is the most prevalent pathotype among E. coli strains causing diarrhea in Mongolian children. J Clin Microbiol. 2004;42:133-9.

29. Chaudhuri RR, Sebaihia M, Hobman JL, et al. Complete genome sequence and comparative metabolic profiling of the prototypical enteroaggregative Escherichia coli strain 042. PLoS One. 2010;5:e8801.

30. Boisen N, Scheutz F, Rasko DA, et al. Genomic characterization of enteroaggregative Escherichia coli from children in Mali. J Infect Dis. 2012:205:431-44

31. Germani Y, Begaud E, Duval P, Le Bouguenec C. Prevalence of enteropathogenic, enteroaggregative, and diffusely adherent Escherichia coli among isolates from children with diarrhea in New Caledonia. J Infect Dis. 1996;174:1124-6.

32. Albert MJ, Faruque ASG, Faruque SM, Sack RB, Mahalanabis D. Case-control study of enteropathogens associated with childhood diarrhea in Dhaka, Bangladesh. J Clin Microbiol. 1999;37:3458-64.

33. Rajendran P, Ajjampur SS, Chidambaram D. Pathotypes of diarrheagenic Escherichia coli in children attending a tertiary care hospital in South India. Diagn Microbiol Infect. 2010;68:117-22.

34. Mansan-Almeida R, Pereira AL, Giugliano LG. Diffusely adherent Escherichio coli strains isolated from children and adults constitute two different populations. BMC Microbiol. 2013;13:22.

35. Afset JE, Bruant $G$, Brousseau R, et al. Identification of virulence genes linked with diarrhea due to atypical enteropathogenic Escherichia coli by DNA microarray analysis and PCR. J Clin Microbiol. 2006;44:3703-11.

36. Yatsuyanagi J, Saito S, Miyajima Y, Amano K, Enomoto K. Characterization of atypical enteropathogenic Escherichia coli strains harboring the astA gene that were associated with a waterborne outbreak of diarrhea in Japan. J Clin Microbiol. 2003:41:2033-9.

37. Dulguer MV, Fabbricotti SH, Bando SY, Moreira-Filho CA, Fagundes-Neto U, Scaletsky IC. Atypical enteropathogenic Escherichia coli strains: phenotypic and genetic profiling reveals a strong association between enteroaggregative E. coli heat-stable enterotoxin and diarrhea. J Infect Dis. 2003;188:1685-94

38. Silva LE, Souza TB, Silva NP, Scaletsky IC. Detection and genetic analysis of the enteroaggregative Escherichia coli heat-stable enterotoxin (EAST1) gene in clinical isolates of enteropathogenic Escherichia coli (EPEC) strains. BMC Microbiol. 2014;14:135.

39. Souza TB, Morais MB, Tahan S, Melli LC, Rodrigues MS, Scaletsky IC. High prevalence of antimicrobial drug-resistant diarrheagenic Escherichia coli in asymptomatic children living in an urban slum. J Inf Secur. 2009;59:247-51.

40. Dias RC, Dos Santos BC, Dos Santos LF, et al. Diarrheagenic Escherichia coli pathotypes investigation revealed atypical enteropathogenic E. coli as putative emerging diarrheal agents in children living in Botucatu, São Paulo State, Brazil. APMIS. 2016;124:299-308.

41. Estrada-García T, Cerna JF. Paheco-Gil let al. Drug-resistant diarrheogenic Escherichia coli, Mexico. Emerg Infec Diseases. 2005;11:1306-8.

\section{Submit your next manuscript to BioMed Central and we will help you at every step:}

- We accept pre-submission inquiries

- Our selector tool helps you to find the most relevant journal

- We provide round the clock customer support

- Convenient online submission

- Thorough peer review

- Inclusion in PubMed and all major indexing services

- Maximum visibility for your research

Submit your manuscript at www.biomedcentral.com/submit

C Biomed Central 